\title{
EL SELLO DOMEYKO
}

\author{
EdUARDO MOYANO B.*
}

Como Presidente de Correos de Chile, es para mi un orgullo participar en el lanzamiento de un sello conmemorativo del natalicio de ese gran polaco-chileno que fue Ignacio Domeyko. Cuando nuestra empresa decide emitir un sello postal en homenaje a una persona se analizan las razones que justifican su puesta en circulación, los valores que el homenajeado representa y la trascendencia de su obra. Así lo hemos hecho con las figuras destacadas de nuestra historia.

Ignacio Domeyko representa una figura multifacética, caracterizada por su gran cultura, su amor, dedicación y aporte a las ciencias y su espíritu y obra orientados a la docencia.

En los albores del siglo XIX, cuando la revolución industrial maravillaba al mundo con sus descubrimientos y la tecnología aplicada facilitaba el trabajo manual, nacía en la ciudad de Vilna en Polonia Ignacio Domeyko, quien tres décadas más tarde, al llegar a Chile, comenzaría a tener para nosotros una importancia trascendental, que a estas alturas, cuando celebramos los 200 años de su natalicio, lo hacen merecedor de importantes reconocimientos y homenajes.

En 1838 llegó a Chile desde sus lejanas tierras este científico, naturalista, matemático, físico, etnólogo, botánico, químico, filósofo, en fin, un intelectual, hombre múltiple para quien la cultura tenía un alcance universal.

Hacia 1837 Carlos Lambert fue encargado por el gobierno de Chile para reclutar a un joven docente para el Colegio de la Serena, que debería oficiar como profesor de química y de minería. El elegido fue Ignacio Domeyko quien, a su llegada al país, se hizo cargo de dictar clases y de construir laboratorios y edificios.

Tanto sus cursos como los textos que publicó en el diario El Araucano, así como sus investigaciones y observaciones de nuestra riqueza

- Eduardo Moyano Berrios, Correos de Chile. 
minera lo convirtieron en una figura central de las ciencias naturales en Chile.

Por su excelencia científica se catalogó a una especie de la flora chilena como "Viola Domeykoana", se bautizó como "Nautilus Domeykus" a un fósil chileno y se denominó como "Domeykita" al arseniuro de cobre, mineral hallado por Ignacio Domeyko en Chile.

El hecho de que nos reunamos en la Sala Ignacio Domeyko de la Universidad de Chile no es de ninguna manera un hecho casual. Domeyko fue un maestro notable y muy generoso en dedicar su tiempo y su vida a enseñar e investigar. En 1843, al gestarse la Universidad de Chile, Ignacio Domeyko estuvo entre los fundadores de la Facultad de Ciencias Físicas y Matemáticas, que tan gran aporte ha hecho en la formación de ingenieros y científicos de variadas especialidades.

En 1847 Domeyko fue designado miembro del Consejo Superior de la Universidad y, tras el fallecimiento de Manuel Antonio Tocornal, fue nombrado Rector de la Universidad, el tercer Rector de esta querida e importante Casa de Estudios.

Ignacio Domeyko pertenece, sin lugar a duclas, a un grupo notable de extranjeros que ayudaron a forjar la joven República de Chile.

Reconocer una vez más la labor realizada en nuestro país por Ignacio Domeyko poniendo en circulación un sello postal que lleva su figura y su nombre nos llena de orgullo como Empresa encargada de vincular a los 15 millones de chilenos y enlazarlos con el Exterior.

Finalmente quiero agradecer a Polonia, la cuna y Patria original de Domeyko, una nación que ha daclo grandes hombres de bien para el desarrollo y progreso en paz de los pueblos, y a la que hemos estado reuniclos permanentemente en aprecio y amistad.

A nombre de la Empresa de Correos de Chile, de todos sus trabajadores, deseo expresar el honor, orgullo y satisfacción de sumarnos a las celebraciones de los 200 años del natalicio de Ignacio Domeyko, en el marco del año internacional de la UNESCO para conmemorar a este insigne polaco. 